\title{
The Application of Fuzzy Comprehensive Evaluation in the Evaluation of Competitive Intelligence Competence of Small and Medium Sized Enterprises
}

\author{
Guiquan Xi, Xiaodong Li and Hong Fu \\ Beijing Institute of science and Technology Information, Beijing, China
}

\begin{abstract}
Based on defining the concept of enterprise competitive intelligence, the fuzzy mathematics theory is used to evaluate the competitive intelligence competence of small and medium sized enterprises. According to the evaluation factor for Small and Medium Sized enterprise competitive intelligence competence, the paper choose corresponding technical index system, and use this Fuzzy Comprehensive Evaluation method to evaluate the performance of Small and Medium Sized enterprise competitive intelligence competence, finally get the result of evaluation. Examples show that the method is effective and has good operability.
\end{abstract}

Keywords-small and medium sized enterprises; competitive intelligence competence; evaluation indicator; fuzzy comprehensive evaluation

\section{INTRODUCTION}

Enterprise competitive intelligence competence is a comprehensive, coordinated, hidden competence, it is not only the result of the interaction of internal factors, but also closely related to the external macro environment and the industry environment. With the rapid development of China's small and medium enterprises, some enterprises have realized the importance of competitive intelligence in their development, competitive intelligence service has been carried out step by step and good results are achieved.

The evaluation of the effect is an important means to measure the level of competitive intelligence competence of small and medium enterprises. However, the research on the evaluation of small and medium enterprises competitive intelligence competence is not a lot, and most of the research was carried out on large and medium-sized enterprises. In this paper, the evaluation of competitive intelligence competence for small and medium enterprises will be discussed.

Fuzzy comprehensive evaluation is a kind of comprehensive evaluation method by the establishment of the membership function and quantitative analysis of contributing factor. In the evaluation of competitive intelligence competence of small and medium enterprises, a large number of evaluation indexes are involved, but here are some indexes which are not easy to measure quantitatively in the evaluation. Therefore, Fuzzy comprehensive evaluation method can be used to evaluate the level of competitive intelligence competence of small and medium enterprises.

\section{II.THE STEPS OF FUZZY COMPREHENSIVE EVALUATION METHOD}

Fuzzy comprehensive evaluation is carried out to quantify the fuzzy index which reflects the evaluation of things by means of constructing fuzzy subsets. Then, calculate the matrix according to the rules of fuzzy transformation. Finally, a general evaluation of the things is given. Specific steps are as follows:

\section{A. Determine the Set of Evaluation Indicators}

$$
\text { P evaluating indicator: } u=\left\{u_{1}, u_{2}, \cdots \cdots, u_{p}\right\}
$$

\section{B. Determine Evaluation Grades}

$$
v=\left\{v_{1}, v_{2}, \cdots \cdots, v_{\mathrm{q}}\right\} \text {, this is gradeset, each grade can }
$$
correspond to a fuzzy subset.

\section{Building the Fuzzy Relation Matrix $R$}

Quantify evaluation factors, $u_{i}(i=1,2, \cdots \cdots, p)$ are quantified after constructing fuzzy subsets, the membership of fuzzy subsets is determined, the fuzzy relation matrix is:

$$
R=\left[\begin{array}{cc}
R \mid & u_{1} \\
R \mid & u_{2} \\
\cdots & \\
R \mid & u_{p}
\end{array}\right]=\left[\begin{array}{cccc}
r_{11} & r_{12} & \cdots & r_{1 m} \\
r_{21} & r_{22} & \cdots & r_{2 m} \\
\cdots & \cdots & \cdots & \cdots \\
r_{p 1} & r_{p 2} & \cdots & r_{p m}
\end{array}\right]
$$

\section{Determining the Weight of Evaluating Factors}

In this paper, we use the Delphi method to determine the weight: $W=\left(a_{1}, a_{2}, \cdots \cdots, a_{p}\right)$.Then normalization, that is $\sum_{i=1}^{p} a_{i}=1 \quad a_{i} \geq 0 \quad i=1,2, \cdots \cdots, n$.

\section{E. Get Fuzzy Synthesize Evaluation Result-Vector}

The weight $\mathrm{W}$ and the $\mathrm{R}$ were synthesized, get fuzzy synthetic evaluation result-vector $\mathrm{B}$ : 


$$
\begin{aligned}
W . R & =\left(a_{1}, a_{2}, \cdots \cdots, a_{p}\right)\left[\begin{array}{llll}
r_{11} & r_{12} & \cdots & r_{1 m} \\
r_{21} & r_{22} & \cdots & r_{2 m} \\
\cdots & \cdots & \cdots & \cdots \\
r_{p 1} & r_{p 2} & \cdots & r_{p m}
\end{array}\right] \\
& =\left(b_{1}, b_{2}, \cdots \cdots, b_{m}\right)=B
\end{aligned}
$$

\section{F. Analyze Fuzzy Comprehensive Evaluation Results}

\section{ESTABLISHMENT EVALUATION SYSTEM OF}

COMPETITIVE INTELLIGENCE COMPETENCE OF SMALL AND MEDIUM SIZED ENTERPRISES

According to the principle of indicator selection, some indexes are selected as the basic index of the evaluation system of competitive intelligence competence of small and medium enterprises.As shown in Figure I.

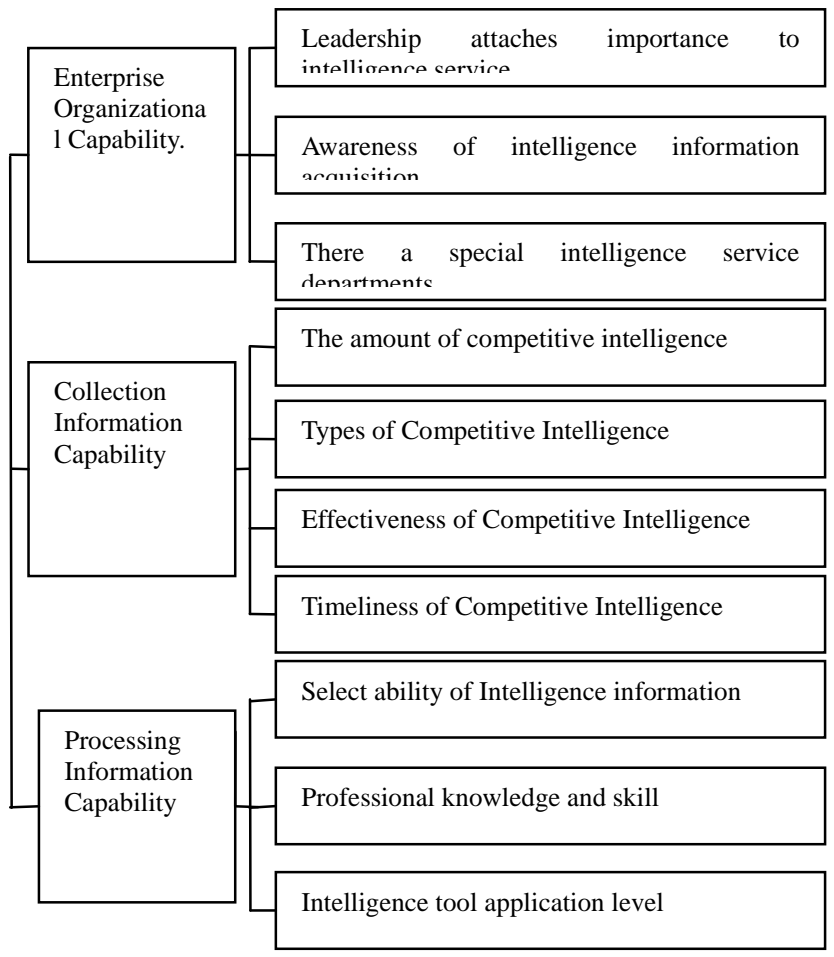

FIGURE I. EVALUATION INDICATORSSYSTEM OF COMPETITIVE INTELLIGENCE COMPETENCE OF SMALL AND MEDIUM SIZED ENTERPRISES

IV. AN EXAMPLE OF COMPETITIVE INTELLIGENCE COMPETENCE EVALUATION FOR SMALL AND MEDIUM SizED ENTERPRISES

\section{A. Establish Evaluation Object}

$P=$ Evaluation of competitive intelligence competence of small and medium sized enterprises

Set Up Evaluation Set $u=\left\{u_{1}, u_{2}, u_{3}\right\}=$ EEnterprise Organizational Capability, Collection Information Capability, Processing Information Capability\}

\section{B. Determine Evaluation Grades}

$$
v=\left\{v_{1}, v_{2}, v_{3}, v_{4}\right\}={ }_{\text {Excellent, Good, Medium, Bad }\}}
$$

C. The Weight of Different Evaluation Indicators by Delphi

\begin{tabular}{|c|c|c|c|}
\hline $\begin{array}{l}\text { First Level } \\
\text { Indicator }\end{array}$ & Weight & Second Level Indicator & Weight \\
\hline \multirow{3}{*}{$\begin{array}{l}\text { Enterpris } \\
\text { eorganizational } \\
\text { Capability }\end{array}$} & \multirow{3}{*}{0.25} & $\begin{array}{l}\text { Leadership Attaches Importance To } \\
\text { Intelligence Service }\end{array}$ & 0.40 \\
\hline & & $\begin{array}{l}\text { Awareness of Intelligence } \\
\text { Information Acquisition }\end{array}$ & 0.22 \\
\hline & & $\begin{array}{c}\text { There a Special Intelligence } \\
\text { Service } \\
\end{array}$ & 0.38 \\
\hline \multirow{4}{*}{$\begin{array}{l}\text { Collection } \\
\text { Information } \\
\text { Capability }\end{array}$} & \multirow{4}{*}{0.41} & $\begin{array}{c}\text { The Amount of Competitive } \\
\text { Intelligence }\end{array}$ & 0.21 \\
\hline & & Types of Competitive Intelligence & 0.17 \\
\hline & & $\begin{array}{l}\text { Effectiveness of Competitive } \\
\text { Intelligence }\end{array}$ & 0.29 \\
\hline & & $\begin{array}{c}\text { Timelinessof Competitive } \\
\text { Intelligence }\end{array}$ & 0.33 \\
\hline \multirow{3}{*}{$\begin{array}{l}\text { Processing } \\
\text { Information } \\
\text { Capability }\end{array}$} & \multirow{3}{*}{0.34} & $\begin{array}{c}\text { SelectAbility of } \\
\text { IntelligenceInformation }\end{array}$ & 0.22 \\
\hline & & Professional Knowledge And Skill & 0.43 \\
\hline & & Intelligence Tool Application Level & 0.35 \\
\hline \multicolumn{4}{|c|}{$W=(0.25,0.41,0.34)$} \\
\hline \multirow{3}{*}{ That is } & \multicolumn{3}{|c|}{$W_{1}=(0.40,0.22,0.38)$} \\
\hline & \multicolumn{3}{|c|}{$W_{2}=(0.21,0.17,0.29,0.33)$} \\
\hline & \multicolumn{3}{|c|}{$W_{3}=(0.22,0.43,0.35)$} \\
\hline
\end{tabular}
method

TABLE I. INDICATOR WEIGHT

D. Establish Evaluation Matrix

Establish evaluation matrix through experts assessments

$$
\begin{aligned}
& R_{1}=\left(\begin{array}{llll}
0.45 & 0.27 & 0.15 & 0.13 \\
0.36 & 0.36 & 0.23 & 0.05 \\
0.22 & 0.47 & 0.22 & 0.09
\end{array}\right) \\
& R_{2}=\left(\begin{array}{llll}
0.14 & 0,45 & 0.27 & 0.14 \\
0.02 & 0.28 & 0.39 & 0.31 \\
0.11 & 0.55 & 0.19 & 0.15 \\
0.21 & 0.39 & 0.31 & 0.09
\end{array}\right)
\end{aligned}
$$




$$
R_{3}=\left(\begin{array}{llll}
0.14 & 0.41 & 0.33 & 0.12 \\
0.08 & 0.32 & 0.45 & 0.15 \\
0.10 & 0.45 & 0.21 & 0.24
\end{array}\right)
$$

E. Comprehensive Evaluation

a) Evaluation vector of organizational capability

$$
\begin{aligned}
B_{1} & =W_{1} \quad R_{1} \\
& =(0.40,0.22,0.38)\left(\begin{array}{llll}
0.45 & 0.27 & 0.15 & 0.13 \\
0.36 & 0.36 & 0.23 & 0.05 \\
0.22 & 0.47 & 0.22 & 0.09
\end{array}\right) \\
& =(0.40,0.38,0.22,0.13)
\end{aligned}
$$

After normalization: $(0.35,0.34,0.19,0.12)$

b) Evaluation vector of Collection Information capability

$$
\begin{aligned}
B_{2} & =W_{2} \quad R_{2} \\
& =(0.21,0.17,0.29,0.33)\left(\begin{array}{llll}
0.14 & 0,45 & 0.27 & 0.14 \\
0.02 & 0.28 & 0.39 & 0.31 \\
0.11 & 0.55 & 0.19 & 0.15 \\
0.21 & 0.39 & 0.31 & 0.09
\end{array}\right) \\
& =(0.21,0.33,0.31,0.17)
\end{aligned}
$$

After normalization: $(0.21,0.32,0.30,0.17)$

c) Evaluation vector of processing information capability

$$
\begin{aligned}
B_{3} & =W_{3} \quad R_{3} \\
& =(0.22,0.43,0.35)\left(\begin{array}{llll}
0.14 & 0.41 & 0.33 & 0.12 \\
0.08 & 0.32 & 0.45 & 0.15 \\
0.10 & 0.45 & 0.21 & 0.24
\end{array}\right) \\
& =(0.14,0.35,0.43,0.24)
\end{aligned}
$$

After normalization: $(0.12,0.30,0.37,0.21)$

d) Comprehensive evaluation vector

$$
\begin{aligned}
A & =W \quad R \\
& =(0.25,0.41,0.34)\left(\begin{array}{l}
0.35,0.34,0.19,0.12 \\
0.21,0.32,0.30,0.17 \\
0.12,0.30,0.37,0.21
\end{array}\right) \\
& =(0.25,0.32,0.34,0.21)
\end{aligned}
$$

The $R$ is: $R=\left[\begin{array}{c}B_{1} \\ B_{2} \\ B_{3}\end{array}\right]$

After normalization: $(0.22,0.29,0.30,0.19)$

Results show, the competitive intelligence competence of the small and medium-sized enterprises excellent degree is 0.22 , Good degree is 0.29 , Medium degree is 0.30 , Bad degree is 0.19 .According to the principle of maximum membership, the medium and small enterprises competitive intelligence competence is "medium".

Generally, at present the sense of competitive intelligence of most small and medium-sized enterprises in our country is still relatively weak. Due to restrictions on policy, funding, personnel, etc., small and medium-sized enterprises can not get the same competitive intelligence as large enterprises. But in order to develop better in the fierce market, Small and medium sized enterprises should establish a competitive intelligence information platform, dynamic tracking of external market environment changes, improve the ability to obtain information.

\section{RESUltS AND DisCUSSION}

In this paper, the evaluation model of competitive intelligence competence of small and medium sized enterprises is established base on fuzzy mathematics. We can see from the results of the example analysis that model is more suitable. Because the evaluation of competitive intelligence competence of small and medium sized enterprises is a complicated work, further research is needed.

\section{ACKNOWLEDGMENT}

This research work was supported by National Social Science Foundation of China under Grant No. 12CTQ046. "Research on Formation Mechanism and Organizational Models of Knowledge-based Network Micro Information”, and Beijing Municipal Financial Project under Grant No. PXM2016_178214_000006. “Capacity Building on Intelligence Processing and Analysis Faced to Text Oriented Information.

\section{REFERENCE}

[1] Baochanghuo, Zhaogang. Discussion on the development trend of Competitive Intelligence [ J].Journal of The China Society for Scientific and Technical Information, 2004 ,(3)

[2] Xjijian,Liuchengping. Fuzzy mathematics method and its application [M].Wuhan:Huazhong University of Science \&Technology Press,2000.

[3] Zhengrong. Analysis on the influencing factors of enterprise competitive intelligence ability [J].Information Science.2007(8).

[4] Zhangjing. A comparative study on the comprehensive evaluation method of enterprise competitive intelligence system [D]. 2010.

[5] Liying. Research on the deconstruction and evaluation of enterprise competitive intelligence ability [J].Information Studies: Theory\& Application. 2014 (7). 